\title{
ILÍDIO DO AMARAL (1924-2017) FUNDADOR, COLABORADOR E AMIGO DA FINISTERRA
}

\author{
MARIa JoÃo AlCOFORADO ${ }^{1}$
}

A Revista Finisterra presta homenagem ao Professor Doutor Ilídio do Amaral, que nos deixou no passado mês de Março, depois de uma longa e brilhante carreira académica, científica e institucional. Exerceu cargos de grande relevância na academia, dignificando a Geografia Portuguesa e contribuiu muito para a sua divulgação no estrangeiro. Falando diversas línguas (incluindo o alemão), estabeleceu contactos em importantes escolas de Geografia estrangeiras, que se vieram a revelar fundamentais para a Escola de Geografia de Lisboa.

Nascido em Angola, o gosto pelo estudo das regiões tropicais iria acompanhá-lo ao longo da vida, tanto nos aspectos da Geografia Física, principalmente a Geomorfologia, como noutros domínios, de que se destaca a Geografia Urbana. As suas obras Santiago de Cabo Verde. A Terra e os Homens (1964) e Luanda. Estudo de Geografia Urbana (1968), várias vezes premiadas, constituem referências que continuam a ser re-editadas. No entanto, o eclectismo de Ilídio do Amaral está bem patente nos diversos interesses de investigação, para além dos já mencionados, de que são exemplo estudos sobre Ambiente, Detecção Remota, Geografia Histórica, Geografia Política e Económica, História, Ensino da Geografia, que culminaram, nos últimos anos em numerosos artigos e quatro livros sobre Geografia Histórica, um dos quais também premiado (Ilídio e Ana Amaral, 2016, nº 271)i.

Foi um excelente Professor, erudito e exigente. As suas aulas eram claras, interessantes e acompanhadas de numerosos esquemas, que desenhava no quadro com grande perícia. A sua dicção pausada permitia ir assimilando os conceitos e ... tomando notas. Nos meados dos anos 1970, era Ilídio do Amaral quem introduzia os caloiros ao estudo da Geografia Física, sendo para eles então o único Professor de Geografia na Faculdade de Letras da Universidade de Lisboa, visto que todas as outras cadeiras do curso eram leccionadas na Faculdade de Ciências. Ouvia e aconselhava os alunos. Iniciava-os também na observação de campo em excursões a pé aos arredores de Lisboa, por exemplo a Loures e Frielas para observação das "costeiras da região de Lisboa". Colaborou, com grande empenho e dedicação, na fundação de diversas Universidades (Porto, Luanda, Cabo Verde, entre outras) e orientou teses sobre os mais variados temas, muitas delas sobre regiões tropicais.

Entre os numerosos cargos que deteve, Ilídio do Amaral foi Vice-Presidente e Presidente em exercício do Instituto de Alta Cultura, Vice-Reitor e Reitor da Universidade de Lisboa e Vice-Presidente da

1 Investigadora do Centro de Estudos Geográficos, Instituto de Geografia e Ordenamento do Território (IGOT) da Universidade de Lisboa. Professora Catedrática Aposentada do IGOT, Universidade de Lisboa, Rua Branca Edmée Marques, 1600-276 Lisboa, Portugal. E-mail: mjalcoforado@campus.ul.pt 
Junta de Investigações Científicas do Ultramar, na década 1970-80, período difícil de transição e de ajuste ao regime democrático. Foi director adjunto do Centro de Estudos Geográficos (CEG) desde a sua fundação em 1943, até que, em 1984, fundou o Centro de Geografia do Instituto de Investigação Científica Tropical (IICT). Prosseguiu os estudos das regiões tropicais, nomeadamente em Cabo Verde, Angola, Moçambique, África do Sul e dinamizou uma equipa de jovens que vieram a seguir as suas pisadas. Permaneceu, no entanto, como colaborador do Centro de Estudos Geográficos (IGOT, Universidade de Lisboa). Mais tarde, foi co-Fundador da Universidade Internacional, de que foi Reitor e do Instituto Superior Politécnico, de que foi Presidente. É notável a sua actividade como Membro da Academia das Ciências de Lisboa, incluindo a sua participação no Conselho Científico do Instituto de Altos Estudos da Academia e a sua colaboração com a Presidência.

\section{ILÍDIO DO AMARAL, FUNDADOR E EDITOR DA FINISTERRA}

Não se fará aqui uma descrição exaustiva da imensa e multifacetada actividade científica e de gestão de Ilídio do Amaral, que o leitor encontrará, por exemplo, na Bibliografia Científica de Ilídio do Amaral, coligida e anotada por Ana Amaral em 2016, assim como no artigo de Jorge Gaspar (neste volume) e no de Teresa Barata Salgueiro, no sítio da Associação Portuguesa de Geógrafos, que Ilídio do Amaral ajudou a criar, e de que foi o primeiro Presidente da Mesa da Assembleia Geral.

Pretende-se agora apenas salientar algumas das iniciativas e acções que Ilídio do Amaral canalizou para a Finisterra. Revista Portuguesa de Geografia, referindo o seu papel de Fundador, com Orlando Ribeiro e Suzanne Daveau, a sua frequente colaboração com a Revista, alguns textos nela publicados e, por fim, mas não menos importante, o apoio eficaz e amigo aos responsáveis da Finisterra.

A publicação de uma revista de Geografia era um velho sonho de Orlando Ribeiro, transmitido a colegas portugueses e estrangeiros desde a fundação do Centro de Estudos Geográficos, em 1943. Vicissitudes diversas só permitiram editar os primeiros volumes em 1966, com o apoio financeiro da Fundação Calouste Gulbenkian. Ilídio do Amaral escreveu mesmo "finalmente preparavam-se os primeiros números da tão sonhada revista de Geografia - a nossa - Finisterra. Revista Portuguesa de Geografia" (Amaral ${ }^{\mathrm{ii}}, 2008$, Finisterra, 86, p. 117). O seu nome terá surgido numa viagem à Galiza, ao cabo com o mesmo nome. Mostrando a vontade de internacionalização dos fundadores, o primeiro número abre com um artigo do geógrafo francês Pierre Gourou, Pour une Géographie Humaine, que viria a ser de leitura obrigatória para algumas gerações de estudantes.

Ilídio do Amaral permaneceu sempre nos corpos dirigentes da Finisterra, sendo ultimamente referido na contra-capa da Revista como "Fundador e antigo Director". As suas numerosas responsabilidades tornaram descontínua a sua participação na gestão da Revista. No entanto, durante os anos em que fiz parte da Comissão de Redacção (1992-1999), ou em que dirigi a Finisterra (2000-2015), Ilídio do Amaral acedeu sempre, com enorme generosidade e empenho, aos convites para escrever textos alusivos a temas específicos e para animar e participar em diversas sessões. Foi numa delas que o ouvi descrever as vicissitudes da produção do primeiro número da Revista, já com a imprescindível ajuda do Dr. António Machado Guerreiro, secretário do CEG (homenageado na Finisterra 86). Ilídio do Amaral acumulou, como ele próprio disse, muitas das "responsabilidades das acções práticas e burocráticas para a concretização do projecto, além de contribuir com Notas e Recensões” (Amaral, 2001, Finisterra, 72, p. 15). Aquelas incluíam também viagens a Alcobaça, "com o manuscrito debaixo do braço", até à Tipografia Alcobacense, para discutir os pormenores técnicos e velar para que tudo ficasse pronto atempadamente. Ilídio do Amaral partiu seguidamente para a Universidade de Munique, onde iria estagiar durante o ano lectivo de 1965-66, seguindo a norma instituída por Orlando Ribeiro de enviar os geógrafos mais promissores a completar no estrangeiro a sua formação, tendo cabido depois a Suzanne Daveau a tarefa, não menos hercúlea, de 
preparar os números seguintes. Com o crescimento do Centro, outros se foram encarregando da gestão e edição da Revista, ajustando a Finisterra a novas realidades, mas Ilídio do Amaral nunca deixou de se interessar por ela. A evolução da Revista é analisada em pormenor no $100^{\circ}$ número da mesma (Alcoforado, Alegria, Queirós, Garcia, Morgado e Vieira, Finisterra, 2015, 100, p. 9-33).

\section{ILÍDIO DO AMARAL, APOIANTE DAS INICIATIVAS DA REVISTA}

Ilídio do Amaral tomou parte em diversas homenagens a Orlando Ribeiro, dando-lhes eco na Finisterra. Em 1981, participou numa sessão por ocasião do Jubileu de "Mestre Orlando" na Faculdade de Letras (Amaral, 1981, Finisterra, 31, p. 5-14) e, em 2008, publicou o ensaio Orlando Ribeiro humanista, a partir de uma palestra que proferira no ciclo de conferências, organizadas na Biblioteca Orlando Ribeiro, no bairro lisboeta de Telheiras (Amaral, 2008, Finisterra, 85, p. 45-56).

No número 63 da Finisterra, dedicado a Suzanne Daveau, Ilídio do Amaral oferece à Colega e co-Fundadora o artigo de cariz histórico intitulado Relações externas congolesas na primeira década do século XVII, em tempos de D. Álvaro II: a Embaixada de D. Garcia Baptista e D. António Manuel, constituído por "apontamentos sobre as relações diplomáticas entre o Congo, Portugal e Espanha e o Vaticano na primeira década do século XVII” (Amaral, 1997, Finisterra, 63, p. 115-131).

Em 2001, festejámos o $35^{\circ}$ aniversário da Finisterra, com um número sobre o tema "Paisagem". O texto de abertura, Finisterra. Uma revista com trinta e cinco anos de prestígio, da autoria de Ilídio do Amaral, constitui um excelente e minucioso balanço da vida da Revista (Amaral, 2001, Finisterra, 72, p. 11-25). Evocou o período difícil do "nascimento" da Finisterra, estabelecendo correspondências com a vida do Centro de Estudos Geográficos, nomeadamente os doutoramentos que iam tendo lugar e cujos resultados mais importantes eram, não raro, convertidos em artigos submetidos à Revista. Foi fazendo o paralelo com os Congressos da União Geográfica Internacional (IGU, na sigla inglesa), em que participava, também como Presidente da Comissão Nacional de Geografia e que iam tendo eco na Finisterra. No que refere ao XXII ${ }^{\circ}$ Congresso da IGU (em Montreal, 1972), dá testemunho de alguma confrontação entre geógrafos 'tradicionais' e outros que adoptavam métodos e técnicas quantitativos e pressupostos teóricos controversos representando a 'revolução da Geografia teorética e quantitativa' (aspas de I. do Amaral, 2001, p. 17). Da década 1980, refere, por exemplo, o XXIVº Congresso da IGU no Japão, cujos temas com mais destaque foram "as alterações climáticas, os desastres naturais e a sua previsão, as questões relacionadas com o ambiente” (p. 20). É interessante verificar que, mais de 30 anos depois, e apesar de grandes progressos técnicos e científicos, continuam a existir fortes travões políticos e económicos à resolução ou mitigação destes grandes problemas ambientais. Do mesmo modo, alude a outros congressos da IGU, o XXVIo em Sydney (1988) e o XXVII em Washington (1992) "onde foram sublinhadas novas orientações científicas e preocupações geográficas globais" (idem). Refere igualmente a Conferência Regional da IGU, organizada pelo CEG em 1998 e de que a Finisterra se fez eco. Termina considerando que a Finisterra "continua firme na sua rota de prestígio" (p. 21) e sublinha a importância da crescente presença da Revista no espaço virtual.

No mesmo volume, Ilídio do Amaral escreve um artigo com o título Acerca de 'Paisagem'. Apontamentos para um debate. Se bem que inicie com a busca de uma definição geográfica, depressa discute a cidade utópica de Thomas More e refere "formas diferentes de ver e sentir a realidade": cita alguns pintores como Monet e Pissarro, que "até serem chamados 'impressionistas', viam-se como 'realistas', de realismo relacionado com as suas maneiras de ver o mundo, de modo não clássico, não literário” (p. 79) e alude ainda a certas peças musicais que não é possível ouvir "sem fazer desfilar mentalmente as paisagens sugeridas" (p. 80). Termina com as paisagens ficcionadas do passado, algumas das quais já se tornaram realidade. Neste curto ensaio, a erudição e a imaginação do autor levam-nos por caminhos inesperados e fecundos. 
Em 2005, Ilídio do Amaral oferece a Carlos Alberto Medeiros, homenageado na Finisterra, por ocasião da sua aposentação, um texto com o título A importância do sector informal da Economia urbana em países de África subsariana, que ilustra a abrangência pluridisciplinar dos seus estudos de Geografia Urbana (Amaral, 2005, Finisterra, 79, p. 53-72).

Posteriormente, o Professor Ilídio junta-se a vários colegas para evocar António Machado Guerreiro na Finisterra (Amaral, 2008, Finisterra, 86, p. 115-118). No texto Recordando António Machado Guerreiro, relembra as suas primeiras décadas na Faculdade de Letras e depois no CEG e as qualidades intelectuais e humanas do Dr. Guerreiro.

Em 2015, a celebração do $50^{\circ}$ aniversário da Revista, que coincidiu com o lançamento do número 100, contou com o apoio e a presença de Ilídio do Amaral. Participando numa mesa-redonda, moderada por Diogo de Abreu e em companhia de Suzanne Daveau (também Fundadora da Revista), Jorge Gaspar e Maria João Alcoforado, o Professor dissertou longamente sobre o nascimento, a vida e... a sobrevivência da Finisterra, actualizando os dados de 2001, felicitando os editores e, num registo mais ligeiro, descrevendo alguns episódios pitorescos e menos conhecidos da vida da Revista. Para toda a equipa editorial, esta sua participação foi um grande incentivo, bem como a conversa subsequente com todos os autores, geógrafos e não-geógrafos, que por ele nutriam simpatia e admiração.

\section{HOMENAGEM DA FINISTERRA A ILÍDIO DO AMARAL}

A jubilação do Professor Ilídio do Amaral, em 1996, como Professor Catedrático de Geografia da Faculdade de Letras da Universidade de Lisboa, não correspondeu - de modo nenhum - a um abrandamento das suas actividades científicas. No entanto, o então director da Finisterra, Professor Carlos Alberto Medeiros, em concordância com a Comissão Científica do CEG, decidiu organizar um número em homenagem ao Professor, limitando os convites aos seus colegas mais próximos. No número duplo 67/68, editado em 1999, no seguimento da Nota de Apresentação de Carlos Alberto Medeiros e de Notas Curriculares Resumidas, coligidas por Ana Amaral, publicaram-se 15 artigos de geógrafos de várias universidades de Portugal, do Brasil e de Moçambique. Os trabalhos editados versam temas caros ao homenageado, metade dos quais sobre regiões tropicais. Na cerimónia de lançamento, na Reitoria da Universidade de Lisboa, Ilídio do Amaral dissertou sobre a sua vida de trabalho e a dos seus discípulos mais chegados, agradecendo as contribuições, o que aliás, voltou a fazer pessoalmente a cada um dos autores.

O Centro de Estudos Geográficos e o Instituto de Geografia e Ordenamento do Território da Universidade de Lisboa dedicaram-lhe nova homenagem, em Novembro 2016. Ilídio do Amaral participou na totalidade do programa, desde as sessões da manhã até ao termo do jantar comemorativo, tendo confessado, em mensagem posterior: "para mim foi um dia de muita comoção perante tantos elogios (...) e a presença de tantos alunos antigos - muitos dos quais não via há bastantes anos - que quiseram tributar o agradecimento ao velho professor". Recebeu, nessa ocasião, a medalha da Universidade, a do IGOT e a da Universidade de Cabo Verde.

\section{ILÍDIO DO AMARAL, AUTOR NA FINISTERRA}

A produção de Ilídio do Amaral na Finisterra é extensíssima e mereceria um estudo aprofundado, que está fora do âmbito desta nota. A partir de alguns exemplos temáticos, pretende-se transmitir o modo como Ilídio do Amaral contribuiu para o prestígio da Revista, publicando nela investigação inédita e inovadora, ao mesmo tempo que teve um papel crucial na difusão bibliográfica, contribuindo para 
a divulgação de títulos dificilmente acessíveis em Portugal e apresentando novas técnicas de estudo (por exemplo a Deteç̧ão Remota, logo nos primórdios da sua utilização em Geografia). Na era da internet e das facilidades concedidas pelas universidades (por exemplo a $B$-on), em que (quase) toda a bibliografia é disponibilizada (quase) instantaneamente, pode ser difícil compreender o problema com que se confrontavam os estudiosos portugueses para se manterem actualizados. Consciente deste facto, Ilídio do Amaral (como aliás os seus Colegas Orlando Ribeiro e Suzanne Daveau) apresentava regularmente as "novidades" científicas, enriquecendo-as com os seus comentários críticos e fazendo resumos de obras que apenas se encontravam disponíveis em línguas de mais difícil acesso, como o alemão. Contribuía também para o ensino da Geografia e a gestão da investigação científica, divulgando as conclusões de reuniões em que participava no âmbito dos diversos cargos que deteve.

Publicou mais nas primeiras décadas de vida da Revista, tendo-se progressivamente afastado (mas nunca desinteressado), porque se ia dedicando a outros projectos, de que a sua vida científica foi fértil (Ilídio e Ana Amaral, 2016; Gaspar, neste número). Multiplicou os seus temas de eleição, interessando-se por Geografia Política, Geografia Histórica, História, temas pedagógicos e de gestão científica, entre outros. Publicou diversos livros e relatórios do CEG e bastantes artigos noutras publicações periódicas. Sendo muitas campanhas de terreno em África ou noutros países tropicais subsidiadas pela Junta de Investigações Científicas do Ultramar (antiga Comissão de Cartografia e futuro Instituto de Investigação Científica Tropical-IICT), os resultados foram publicados com a chancela daquela instituição. A revista que recolheu mais artigos de Geomorfologia das regiões tropicais de Ilídio do Amaral foi Garcia de Orta. Série de Geografia, que Ilídio do Amaral fundou em 1973.

No entanto, Ilídio do Amaral reservou para a Finisterra muitos importantes artigos em temas da sua predilecção, de que se darão alguns exemplos.

\section{Geomorfologia das Regiões tropicais}

A Geomorfologia das regiões tropicais interessou desde o início Ilídio do Amaral. Foi o principal tema dos seus estudos em Munique e, no ano a seguir à chegada a Portugal, brinda a Finisterra com um artigo de síntese sobre as Tendências da Geomorfologia (Amaral, 1967, Finisterra, 3, p. 17-38), enriquecido certamente com material recolhido no seu estágio. Dá uma visão sintética da evolução da Geomorfologia, abrindo mesmo para os problemas de quantificação. A visão bíblica catastrofista da génese das formas do relevo só viria a ser posta em causa no séc. XVIII por Hutton (1726-97) e, só no fim do séc. XIX, os estudos de vários investigadores americanos, que culminaram com a teoria de W.M Davis da "erosão normal", levaram a aceitar a acção fluvial como agente de erosão (sentido lato). A Geomorfologia tornou-se então independente da Geologia. Depois de se terem preocupado com a definição estrutural das formas de relevo, os geomorfólogos interessaram-se pela dinâmica externa, como agente do modelado. J. Tricart foi um impulsionador destes estudos nas décadas 1960 e 70. Compreendeu-se que o clima tem (e teve) um papel primordial no modelado. Daí decorreu a definição das regiões morfogenéticas de J. Büdel (1963). Também na mesma altura se dava ênfase a "um interesse crescente pela verificação rigorosa dos processos, dos aspectos quantitativos dos fenómenos" (p. 37), embora existissem "severas restrições à aplicação do aparelho matemático em Geomorfologia" (que, desde então, se têm vindo a resolver). Este artigo foi citado logo em 1968, nos Cahiers de Géographie du Québec, na síntese de $\mathrm{P}$. Cotet, Les réalisations de la géomorphologie moderne et le problème de la pénéplaine.

São publicadas na Finisterra numerosas recensões de novos livros de Geomorfologia das regiões tropicais (às vezes obras de conjunto de Geografia Física), além de sínteses de teses de doutoramento, como a da sua orientanda Maria Eugénia Moreira, sobre a Bacia do Rio Umbelúzi (Moçambique). As recensões são minuciosas, mas críticas, ficando claro o mérito e as fraquezas das diferentes obras e das interpretações dos autores. Por exemplo, faz crítica incisiva do livro Morphology of the Earth de Lester 
C. King (de 1962), que recusava a influência do clima no modelado, apesar de ter o cuidado de apontar os pontos que lhe pareceram mais positivos na obra (Amaral, 1966, Finisterra, 1, p. 111-114). Será depois a vez das Publicações recentes de Geomorfologia dinâmica (Amaral, 1966, Finisterra, 2, p. 267-273), de Livros novos de Geografia Física (Amaral, 1966, Finisterra, 2, p. 135-137 e 1967, Finisterra, 4, p. 266-269), em que refere livros de Arthur Strahler, que se tornariam obrigatórios em certas cadeiras, manuais alemães e temas da geografia soviética. Seguem-se Progressos em Geomorfologia (Amaral, 1968, Finisterra, 5, p. 101-106) e ainda Geomorfologia tropical (Amaral, 1983, Finisterra, 36, p. 389-392), entre outras. Dá a conhecer obras editadas em várias línguas (francês, inglês e alemão, italiano), essenciais para difundir a evolução das teorias e métodos da Geomorfologia de então e também as acesas discussões entre diferentes "correntes". Sempre atento e interessado, publica mais tarde uma longa síntese denominada Ler Cabo Verde. Notas e Reflexões (Amaral, 2004, Finisterra, 78, p. 87-98), em que refere e comenta obras recentes de Geografia Urbana e Rural, Geomorfologia, Alterações Climáticas e ainda um Dicionário Português-Francês, que foca as particularidades da "língua portuguesa escrita em África e do crioulo". No que toca à Geomorfologia refere a tese de doutoramento de F. L. Costa que "acentua as ligações entre a investigação e a sua aplicação".

Baseado nestes conhecimentos teóricos e em longas campanhas de investigação no terreno, Ilídio do Amaral fez vários estudos em regiões tropicais, uma dezena dos quais publicados na Garcia de Orta. Série de Geografia, incluindo os célebres trabalhos sobre Inselberge (Ilídio e Ana Amaral, 2016, nº 70 e 111), elogiados por Orlando Ribeiro. Alguns trabalhos neste tema são também difundidos em relatórios do Centro de Estudos Geográficos (Linha de Acção n 5, então dirigida por Ilídio do Amaral). Na revista Garcia de Orta, outros artigos pioneiros para a compreensão da Geomorfologia tropical são dados à estampa, nomeadamente sobre fenómenos cársicos no NW de Angola ( $\left.\mathrm{n}^{\circ} 110\right)$, estudos de formas litorais em Cabo Verde ( $\left.n^{\circ} 155\right)$, fluviais em Moçambique ( $\left.n^{\circ} 157\right)$ e modelado desértico, incluindo a acção eólica ( $\mathrm{n}^{\circ}$ 169, 203 e 229). Em 2006 volta a publicar na Finisterra um artigo de fundo $O$ rio Cambongo-Negunzo e os seus afluentes (Amaral, Finisterra, 2006, 82, p. 15-48), para mostrar a complexidade dos padrões de drenagem em Angola, numa área semi-árida com relevos residuais de tipo Inselberge, formações quartzíticas e espaços de modelado cársico. Neste artigo, separado dos anteriores por cerca de duas décadas, e a partir deste caso de estudo, o Autor faz uma síntese dos seus trabalhos sobre a Geomorfologia tropical, correlacionando os factores de dinâmica externa e interna para explicar a génese e evolução das formas de relevo.

\section{Geografia urbana das regiões tropicais}

No que diz respeito à Geografia urbana de regiões tropicais, Ilídio do Amaral escreve sobre Johannesburg. Do campo mineiro à conurbação (Amaral, 1966, Finisterra, 2, p. 240-256), Beira, cidade e porto do Índico (Amaral, 1969, Finisterra, 7, p. 76-93) e, mais tarde, sobre o Fenómeno da urbanização em Angola (Amaral, 1978, Finisterra, 25, p. 43-76) e sobre Luanda e os seus 'muceques'. Problemas de Geografia urbana (Amaral, 1983, Finisterra, 36, p. 293-325).

A cidade de Joanesburgo é apresentada como um raro caso de sucesso, que conseguiu escapar ao comércio incerto do ouro, para se transformar (nos anos 1960) numa grande metrópole, centro de uma grande e poderosa conurbação. São, no entanto, conhecidos os problemas que a cidade enfrenta hoje em dia. Quanto à cidade da Beira, banhada pelo Oceano Índico, pode seguir-se a sua evolução desde a fundação de um posto militar em 1887 até ao fim da década 1960. A população urbana caracterizava-se pelo cosmopolitismo, a actividade do porto crescia (era a passagem para o Oceano dos países limítrofes interiores) e as actividades económicas e agrícolas prosperavam. No entanto, o autor conclui que a cidade não conseguiu organizar em seu redor uma área urbana estruturada. $\mathrm{O}$ mesmo aconteceu em 
Luanda, cujos problemas dos muceques (ou musseques) continuavam (e continuam?) a necessitar de ser abordados e resolvidos, apesar das modificações ocorridas aquando da independência de Angola. Se bem que datados no tempo, estes estudos interessantes e incisivos têm servido de ponto de partida para actualizações recentes da investigação. Na perspectiva actual em que as métricas de avaliação da produção científica estão na ordem do dia (e - para o bem e para o mal - influenciam classificações e subsídios), verifica-se que este artigo, escrito em português, foi citado 15 vezes (em publicações referenciadas pelo Google Scholar). A difusão era na altura feita à base de permutas e de separatas, que os autores enviavam pelo correio aos colegas interessados ou distribuíam nos congressos.

Tal como no caso dos estudos de Geomorfologia, Ilídio do Amaral publica numerosas recensões e notas de leitura sobre o estudo geográfico das cidades. Logo no segundo número faz referência ao Central Business District (CBD) a propósito de obras sobre Cape Town e cidades da Índia (Amaral, 1966, Finisterra, 2, p. 284-287), numa altura em que o conceito de CBD seria certamente pouco conhecido entre nós. No mesmo número, faz a recensão do livro de Jean Gottman intitulado Megalopolis, sobre a enorme "concentração urbana" no NE dos Estados Unidos, livro esse que teria repercussões em muitos estudiosos desta matéria em todo o Mundo (Amaral, 1966, Finisterra, 2, p. 131-135). Em 1969, publica Notas de leitura em Geografia Urbana (Amaral, 1969, Finisterra, 7, p. 125-134), apresentando livros italianos recentemente dados à estampa e uma compilação editada no Reino Unido relativa à Urbanização e os seus problemas em cidades de praticamente todos os continentes, destacando as contribuições mais interessantes e criticando construtivamente alguns pontos. Em 1985, surgem Notas bibliográficas sobre cidades de África Tropical (noutra publicação) e, na Finisterra, Notas bibliográficas sobre cidades do Terceiro Mundo em três partes (Amaral, 1985, Finisterra, 39, p. 163-172 e 40, p. 368-373 e ainda 1987, 44, p. 361-370). No mesmo ano escreve uma recensão da tese da sua doutoranda Teresa Barata Salgueiro sobre Mercado de Habitação e Estrutura Urbana na Área sub-urbana de Lisboa (Amaral, 1985, Finisterra, 39, p. 163-172). Mais tarde, refere várias obras sobre a cidade da Praia na síntese bibliográfica Ler Cabo Verde. Notas e Reflexões (Amaral, 2004, Finisterra, 78, p. 87-98).

\section{Alterações climáticas e riscos naturais}

Os textos sobre este assunto demonstram a sensibilidade do cientista para com a inconstância do clima, os danos potenciais ou reais de eventos meteorológicos extremos e a problemática das alterações climáticas e dos riscos naturais.

Logo no primeiro número da Revista, Ilídio do Amaral apresenta um conjunto de textos a que deu o título Flutuações climáticas no globo (Amaral, 1966, Finisterra, 1, p. 114-119), onde refere dois livros sobre os climas do passado e as comunicações apresentadas no Colóquio Changes of Climate (Roma, 1961), organizado pela Organização Meteorológica Mundial e pela UNESCO. Nas obras consultadas (de M. Schwarzbach e C. Brooks) é definida Paleoclimatologia, são descritas as alterações climáticas nos períodos geológicos e sintetizadas as suas possíveis causas naturais (terrestres, planetárias e extra-terrestres). Na reunião da UNESCO, discutem-se os métodos de estudo das alterações climáticas, que deverão ser ajustados às diversas escalas temporais das mesmas, a variação e variabilidade do clima no período instrumental e a utilidade de dados documentais. Na busca das causas, é já salientado por H. Flohn que "o aumento do teor de anidrido carbónico $\left[\mathrm{CO}_{2}\right]$ da atmosfera terrestre no decorrer dos últimos cem anos [em relação a 1960] é provavelmente uma das causas da flutuação climática recente". Fica claro que as principais questões das alterações climáticas e do seu estudo estavam lançadas nesta altura e que Ilídio do Amaral teve clara percepção da importância do tema, dedicando-lhe várias páginas para incentivar trabalhos interdisciplinares (que só bem mais tarde se vieram a concretizar, como por exemplo o projecto EU Millennium no início do século XXI). Mais tarde, continuando atento aos grandes problemas mundiais, Ilídio do Amaral foca os debates ambientais na Conferência da ONU, em 1992, em 
que "foram adoptadas a Declaração do Rio, a Agenda 21 e a Declaração Oficial de Princípios para um Consenso Global sobre a Gestão, a Conservação e o Desenvolvimento Sustentável de todos os tipos de florestas (..)". Alude igualmente ao protocolo de Kyoto (1997), referindo que estes problemas de Ambiente e Desenvolvimento são objecto de estudo privilegiado para geógrafos (Amaral, 2001, Finisterra, 72, p. 11-25). A definição de clima, ou seja, a sucessão habitual de estados do tempo num determinado local, inclui já a noção de variabilidade; em ocasiões de maior amplitude dessas variações, ocorrem eventos extremos potencialmente nefastos para as populações e que - a realizarem-se as projecções climáticas - tenderão a tornar-se mais frequentes nas regiões do Sul da Europa: mais episódios de precipitação intensa, mais secas, mais ondas de calor. Em 2004, volta a este tema a propósito de Cabo Verde (Amaral, 2004, Finisterra, 78, p. 87-98), referindo as acções em curso e projectadas para mitigação e adaptação às alterações climáticas.

Um ano depois da publicação do texto sobre as flutuações climáticas, tiveram lugar precipitações muito intensas na região de Lisboa. Ilídio do Amaral foi dos primeiros a escrever numa revista científica sobre As inundações de 25/26 de Novembro de 1967 na região de Lisboa (Amaral, 1968, Finisterra, 5, p. 79-84). Foram as inundações mais mortíferas do século XX na região de Lisboa (embora o número exacto de vítimas não tenha chegado a ser divulgado) e ocasionaram avultados danos materiais. $\mathrm{O}$ artigo foi escrito imediatamente depois do acontecimento, apoiado em dados de precipitação fornecidos pelo Instituto de Meteorologia, trabalho de campo, fotografias próprias e informações sedimentológicas facultadas pelo geólogo A. M. Galopim de Carvalho (Finisterra 102). Este texto foi até hoje alvo de 27 citações referidas no Google Scholar, em publicações nacionais e internacionais, 3 das quais em conceituadas revistas internacionais (Journal of Hydrology, Climates of the Past, Mitigation and Adaptation Strategies for Global Change). Como causas do desastre, Ilídio do Amaral refere: a intensidade da precipitação na noite de 25 para 26 de Novembro de 1967, o relevo e a forma da bacia de drenagem, o facto de os solos já estarem saturados pelas chuvas de Outubro e Novembro e dos leitos estarem atulhados de materiais detríticos; numa outra ordem de grandeza, são apontados os erros de ordenamento do território (por exemplo, construção de edifícios em leitos de cheia ou nas vertentes instáveis), entre muitas outras causas (p. 83). Apoiado no Boletim Meteorológico Diário, Ilídio do Amaral descreve igualmente a trajectória da depressão que afectou Portugal e mais particularmente a região de Lisboa. Muitos trabalhos deste género se seguiram até hoje, mas Amaral terá sido pioneiro em mostrar que estes estudos podem ter aplicação prática evidente. O País ficou em choque, mas foi a partir daí que começaram a ser tomadas medidas de prevenção e de resposta a calamidades deste tipo, de modo que as cheias de 19 de Novembro de 1983 na mesma área, originaram muito menor número de vítimas mortais. Na altura em que se está no rescaldo dos terríveis fogos florestais iniciados a 17 de Junho de 2017 no Centro de Portugal, deseja-se que a curto, a médio e a longo prazo haja vontade política para tomar efectivamente medidas para evitar que elementos meteorológicos adversos voltem a ter as mesmas consequências, analisando, discutindo e aplicando as sugestões dos inúmeros estudos e relatórios já divulgados sobre o assunto. ${ }^{i i i}$

Na mesma linha, e noutras publicações, Ilídio do Amaral também trata dos riscos naturais, por exemplo, no caso das restingas e das escarpas "abarrocadas" de Luanda (Territorium, 2002), e dos constrangimentos infringidos pelo clima às populações de Cabo Verde e suas actividades, presentes em diversos escritos e conferências.

\section{Outros temas}

Escolheram-se os três tópicos anteriores para ilustrar a riqueza da produção de Ilídio do Amaral na Finisterra, complementando artigos de fundo, tanto teóricos como de investigação, com notas e recensões que também se queriam pedagógicas e que foram essenciais para estudiosos portugueses. Poderiam, noutra ocasião, tratar-se de outros eixos temáticos, tal é a variedade de produção do 
Professor Ilídio do Amaral, assim como de outras notas e recensões, de que se destacam dois longos textos sobre A Geografia de Portugal nova e monumental, organizada por Carlos Alberto Medeiros. Fica o testemunho de que Ilídio do Amaral era um investigador erudito, laborioso, precursor em muitos temas, rigoroso e informado. A Finisterra orgulha-se de ter sido um veículo privilegiado da sua produção científica.

Recordarei sempre com saudade o Professor Ilídio do Amaral. Foi ele que guiou os meus primeiros passos no curso de Geografia, quando, ainda no secundário, fui levada aos colóquios do Centro de Estudos Geográficos por Ruben A., amigo da minha família e dos Geógrafos, nomeadamente dos Professores Orlando Ribeiro e Ilídio do Amaral. Fui sua aluna e, sabendo que eu iria um ano para a Alemanha, ajudou-me com conselhos, indicações (e traduções) úteis. Fui depois sua assistente (com Maria Helena Dias) e sua colega. Não se coíbia de fazer notar frontalmente algo que não lhe agradava, mas aceitava explicações. Esteve nas provas do meu Doutoramento e acompanhou sempre a minha carreira com solicitude e Amizade, que não esquecerei.

\section{REFERÊNCIAS BIBLIOGRÁFICAS}

Amaral, I., \& Amaral, A. (2016). Bibliografia Científica de Ilídio do Amaral. Centro de Estudos Geográficos, Lisboa.

i Nas obras não referentes à Finisterra, citadas por Ilídio do Amaral e Ana Amaral (2016), será apenas indicado o número de ordem na respectiva lista bibliográfica.

ii Nas referências bibliográficas referentes à Finisterra, omitir-se-á o título da obra, por este ser indicado no texto.

iii Refira-se que o número 53-54 da Finisterra, editado em 1992, foi dedicado exclusivamente aos problemas da "Floresta em Perigo", e contém cinco artigos sobre o perigo de incêndios florestais por peritos portugueses e franceses, que estabelecem a comparação com incêndios do Sul da França e descrevem métodos de prevenção adequados, nomeadamente a gestão dos espaços florestais nas escalas regional e local. 